\title{
PROBLEMS WITH DETERMINATION OF FUGITIVE EMISSION OF POLYCYCLIC AROMATIC HYDROCARBONS FROM COKE OVEN BATTERY
}

\author{
Rafał Bigda ${ }^{1}$, Aleksander Sobolewskii ${ }^{1}$, Jolanta Telenga-Kopyczyńska' ${ }^{1}$, Krzysztof Słowik $^{1}$ \\ 1 Institute for Chemical Processing of Coal, Zamkowa 1 St., 41-803 Zabrze, Poland, e-mail: bigda@ichpw.pl
}

Received: 2016.12.23

Accepted: 2017.01.16

Published: 2017.03.01

\begin{abstract}
Coke oven battery is a complex and multifaceted facility in terms of air pollutant emissions. As far as stack or quenching tower does not cause major difficulties of emission measurement, the fugitive emission measurement from such sources as battery top elements (charging holes, ascension pipes) or oven doors is still complicated and not fully solved problem. This article presents the discussion concerning main problems and errors likely to be made in particular stages of procedure of fugitive emissions characterization from coke oven battery (selection of sampling points, sampling itself, measurement of air velocity over battery top and laboratory analyses). In addition, results of concentrations measurements of selected substances characteristic for the coking process (naphthalene, anthracene, 4 PAHs and TSP) originating from fugitive sources of coke oven battery and subjected to reporting under the E-PRTR are presented. The measurements were carried out on a coke oven battery top in points selected on the basis of the preceding detailed air convection velocity measurements over the battery top. The results of the velocity measurements were compared with results of numerical modelling using CFD software. The presented material is an attempt to cross-sectional presentation of issues related to the quantitative evaluation of fugitive emission from coke oven battery, discussed on the example of PAHs emission as a group of substances characteristic for coking of coal.
\end{abstract}

Keywords: coke oven battery, industrial emission, fugitive emission, PAHs, coking plant

\section{INTRODUCTION}

In 2006, in all member-countries of the European Union, directive No. 166/2006 of the European Parliament and Council from 18 January 2006 came into force concerning the European Pollutant Release and Transfer Register (EPRTR) [Regulation EC 2006]. The directive introduced a new obligation to report data on emission and transfer of pollutants to the environment. EU member-countries were obliged to establish National Pollutant Release and Transfer Registers constituting elements of the E-PRTR. Data concerning pollutants emission and transfer are transmitted annually by individual plants to the proper authorities. National administrative bodies check data reliability and credibility and pass them to the European Commission and the European En- vironment Agency (EEA) who publish them on the E-PRTR website (http://prtr.ec.europa.eu).

In accordance with E-PRTR principles the operator of each installation is obliged to monitor emissions and to report them. In the process of determining emission levels of particular substances from an individual technology operation any operator makes use of different (available) methods taking their credibility and applicability for a said object and costs into consideration. Under this situation (especially where there is a lack of appropriate standards or when direct measurements are too expensive) operators are often forced to estimate the emission level that should be based on credible premises.

Since 2007, all coke plants (listed in enclosure No. I under in the item: Coke ovens [Regulation EC 2006]) have been made liable to report within 
the framework of the above directive. They are obliged to monitor emissions of all the pollutants determined in directive E-PRTR (60 substances) and in papers to report only those emissions and transfers that have the level surpassing boundary values as per enclosure No. II [Regulation EC 2006]. The E-PRTR directive's target is to improve public access to information concerning environment pollution through the creation of a consistent and integrated Pollutant Release and Transfer Register.

Due to the lack of uniform procedures of pollutants emission monitoring a critical verification of currently applied emission factors and unbiased justification of the adopted methodology simplifications for measurements and estimation of stack and fugitive emission are necessary. Developing an adjusted system requires answering numerous questions. One should firstly settle which pollutants are characteristic and especially quantitatively significant for particular emission sources and by that reason, which of them should be balanced. The unification of methods of emission balancing for coke making process is necessary through a development of consistent and uniform measurement methods and verification of emission factors for individual sources [Telenga-Kopyczyńska et al. 2010].

The aim of the paper is to introduce issues concerning measurement and calculation of fugitive emission from coke oven battery in the example of selected pollutants characteristic for the process of coal pyrolysis, such as PAHs (including anthracene, naphthalene and benzo(a)pyrene).

\section{COKE-MAKING IN POLAND}

Polish coke-making is considered young, as far as the age of the production base is concerned. The average age of a coke oven battery in Poland is the lowest among European Union countries and comes to some 13 years (in 2015). Eight new batteries have been built within the last 12 years (each one of a productivity of at least 700,000 tons of coke per year). Regularly performed repair actions maintain productivity of older batteries and prolong their production life. Almost $60 \%$ of coke in Poland is produced in gravitational system batteries of PWR-63 [Sobolewski and Sciążko 2006]. Polish coke oven batteries differ substantially, as far as their construction, technology, productivity and the level of devel- opment are concerned. They are linked by a kind of fuel gas - all of them are heated by coke-oven gas [Telenga-Kopyczyńska et al. 2009].

The biggest coke plants in Poland: ArcelorMittal Poland JSC - Division Zdzieszowice, Coke Plant "Przyjaźń" Ltd., coke plants belonging to Coke Chemical Complex "Zabrze" JSC, as well as coke plant ArcelorMittal Poland JSC - Division Krakow are mainly producers of high quality blast-furnace coke. Coke plant "Jadwiga" of Coke Chemical Complex "Zabrze" JSC specializes in the production of low-phosphorus broken coke. Coke Plant Czestochowa Nowa Ltd. Plant and CARBO-KOKS Ltd. produce partly blast-furnace coke of weaker mechanical properties and partly industrial-domestic coke. In turn, Coke Plant „Victoria” JSC specializes in the production of high quality foundry coke. The biggest production capacities are to be found in two coke plants: ArcelorMittal Poland JSC - Division Zdzieszowice and Coke Plant Przyjazn Ltd. with overall productivity in the range of $70 \%$ of the total capacity in Poland [Hereźniak et al. 2008].

For the last few years (with the exception of the crisis in 2009) the production of coke in Poland has been running at the level of ca. 10 million tons per year (Table 1), locating Poland in the first place in the EU. Poland is also one of the world's biggest coke exporters.

Polish coking plants differ in terms of the following features:

- productivity (small or big plants),

- age and technical condition,

- charging system (gravitational or stamping),

- coke cooling system (wet or dry),

- association with steel works (independent coke plants or integrated with steel works).

Table 1. Number of batteries and real production capacity of Polish coke plants (2015)

\begin{tabular}{|l|c|c|}
\hline \multicolumn{1}{|c|}{ Coke Plant } & $\begin{array}{c}\text { No. of } \\
\text { operating } \\
\text { batteries }\end{array}$ & $\begin{array}{c}\text { Production } \\
\text { capacity } \\
\text { (mln t) }\end{array}$ \\
\hline $\begin{array}{l}\text { ArcelorMittal Poland JSC - } \\
\text { Division Zdzieszowice }\end{array}$ & 8 & 4.32 \\
\hline Coke Plant Przyjazn Ltd. & 4 & 2.85 \\
\hline Coke Plant „Victoria” JSC & 5 & 0.67 \\
\hline $\begin{array}{l}\text { Coke-Chemical Complex } \\
\text { „Zabrze” JSC }\end{array}$ & 3 & 1.38 \\
\hline $\begin{array}{l}\text { Coke Plant Czestochowa Nowa } \\
\text { Ltd. }\end{array}$ & 2 & 0.73 \\
\hline $\begin{array}{l}\text { ArcelorMittal Poland JSC - } \\
\text { Division Kraków }\end{array}$ & 1 & 0.75 \\
\hline CARBO-KOKS Ltd. & 1 & 0.26 \\
\hline Total & 24 & 10.96 \\
\hline
\end{tabular}


Thanks to the above features, Polish cokemaking mirrors the diversity of the European coke-making industry and is thus an appropriate place to carry out different comparative studies.

\section{EMISSION FROM COKE OVEN BATTERY}

Directive [Regulation EC 2006] determines 60 air pollutants, but EU experts recognize only 22 of them as characteristic for the process of coke making [Guidance Document 2006]. According to the system guidelines, each installation should be aware of credible data confirming the emission levels. In the case of a coke plant - taking common availability of methods determining stack emission under consideration - a key problem is credible determination of the level of fugitive emission. Therefore, the efforts have been made in Poland to develop a proper methodology of fugitive emission determination.

The main assumption has been to make measurements over coke oven battery top, since this is the place where cumulates heat and emission impact of all individual operations connected with coke production. It has been decided to put emphasis on determination of emission of total suspended particles (TSP). Dust is the most important element of fugitive emission and in addition it is possible to determine 12 out of 22 substances characteristic for coke production (in accordance with Regulation EC 2006): PM10, 8 heavy metals, anthracene, naphthalene and 4 PAHs (benzo(a) pyrene, benzo(b)fluoranthane, benzo(k)fluoranthane and indeno(1,2,3-cd)pyrene). In discussion on the obtained results one has concentrated on measurement of PAHs emission. The following facts were premises for this decision:

- monitoring of PAHs emission is covered by an obligatory E-PRTR reporting,

- there is a lack of accepted and verified methods of determination of fugitive PAHs emission,

- substances described as PAHs are characteristic for the process of coal pyrolysis,

- they create a significant threat to human health.

Taking the above under consideration, fugitive emission measurements have been carried out on battery tops of selected Polish coke plants operating as well in charging as in stamping systems.

\section{DETERMINATION OF FUGITIVE EMISSION FROM COKE OVEN BATTERY}

A coke oven battery forms an exceptionally complicated and heterogeneous object from the point of view of air pollutants emission. While emission from stack sources, such as chimneys or coke-quenching towers does not cause bigger measurement difficulties, fugitive emission is still a problem that has not been fully solved.

There were some attempts made in world coke making industry to measure fugitive (non-stack) emission from coke oven battery. One of the first and the widest approach within this area was made during a series of research studies funded by ECSC (European Coal and Steel Community ECSC, currently RFCS - Research Fund for Coal and Steel) carried out in $80 \mathrm{~s}$ of $20^{\text {th }}$ century [Klein 1990; Thomas 1990; Eisenhut 1990; Hermia et al. 1992; Antill 1991]. During these measurements there were few technical solutions invented for fugitive emission measurements from coke oven battery, including point emission sources. For this purpose various kinds of measurement solutions were developed aimed at locally "catching" fugitive emission. Various examples may be [Fischer 2001]: covering closed oven doors, funnels on closed charging holes, ascension pipes hoods. Due to the large number of individual emission sources on the battery, the above solution prevented the measurement of each of them. Therefore, for measurements the most representative points were chosen and the obtained results were referred to visual observation.

In Japanese coke making there is another approach used for fugitive emission estimation, based on 4 points scale visual observation of leakages from oven doors [Okuda 2006]. Each point has its weight depending on determined emission intensity. Eventually, the averaged GEI (Gas Emission Index) is calculated for fugitive emission from chambers doors.

Recently, for purposes of fugitive emission characterization Optical Remote Sensing (ORS) method has been used, mainly for large area sources of emission, as landfill sites [EPA 2006; Thorneloe 2007]. But ORS method is also used in industrial conditions for determination of fugitive emission profile from coke oven battery at South Taiwanese coking plant [Chitsan et al. 2007]. During the measurements Open-Path Fourier Transform Infrared (OP-FTIR) spectroscopy was used. Measurement of selected gases $\left(\mathrm{NH}_{4}, \mathrm{CO}\right.$, 
$\mathrm{CH}_{4}, \mathrm{C}_{2} \mathrm{H}_{6}, \mathrm{C}_{2} \mathrm{H}_{4}$, acetylene, propylene, cyclohexane and o-xylene) concentrations were carried out on Still coke oven battery based on the procedure of EPA TO-16. Measuring system was located at the top of the battery on the coke side. As a result, hourly distribution of concentrations of measured gases was obtained that reflected well the variability of their fugitive emission over battery top. The authors confirmed the possibility of using OP-FTIR method for continuous monitoring of selected gases, but due to high variations of the obtained concentrations and discrepancy with the results of other researchers (using other measurement techniques), the method requires verification and further research.

The above examples show how different approaches may be applied to characterize the level of fugitive emission from coke oven battery. However, each method usually generates different results, because it focuses on different aspects of fugitive emission (visual estimation, point source measurement, estimation of total concentration of fugitive pollutants in atmosphere above battery). In addition, each method generates errors, which strictly depends on a few key factors:

- proper selection of the number and location of sampling points,

- correct (credible and repeatable) sample,

- professional instrumental analysis,

- correct determination of the field of air convection velocity over the battery top.

Therefore, starting determination of fugitive emission from a coke oven battery one should analyse in detail at least above factors that have a significant impact on the final result of work.

Below, all the factors are discussed one by one concentrating on their influence on errors occurred during emission determination.

\section{SAMPLING LOCATION}

The diversity of sources of fugitive emission translates into the forming of a heterogeneous field of concentration of emitted substances over the battery top. When a diversification of their emission in the function of time and the influence of atmospheric conditions are taken into account, a very dynamic system is obtained, which additionally hinders emission determination.

Therefore, in the first approach to emission measurements it is important to determine the average level of concentration of individual pol- lutants over the battery top, as the effect of their emission from individual sources.

The next step - but made only at the stage of investment and technology planning to restrict emission - should be measurements from individual sources. Initially adopted methods of emission summing from individual sources usually give non-representative results and might lead to significant errors.

In practice, determination of the emission levels is difficult because of the lack of acknowledged measurement methods for fugitive emission. Therefore, in accordance with EU BAT and US EPA reference documents, as well as with national practice, combination of measurement and emission factors taking under consideration specific features of particular installations are applied to evaluate emission levels.

In view of the above problems, the choice of sampling location on a coke oven battery is a challenge for measuring staff. One of the main problems is to determine such measurement points that:

- take into account the influence of maximum number of significant sources of fugitive emission,

- are representative,

- do not disrupt the process of coke production.

Following by the above premises one has deployed 9 samplers on 3 chambers on the whole width of the battery top (chambers 3-7 counting from the service platform) with 1 chamber interval (Fig. 1 and 2). Such a location allows carrying out sampling with no impediment from machines working on the battery top.

Three 2-hour measurement series have been carried out on two batteries: one old (shortly before shutting down) and one new (after just starting up) operating in charging system. Figure 3 presents emission levels of 16 PAHs determined on the basis of concentrations determined in particulate-organic samples collected on glass-fibre filters in 9 points on the battery top.

The measurements allowed drawing conclusion that it is difficult to maintain repetitiveness of the obtained results. Even though the points were located in proximity (Fig. 1), local disturbances of air flow over the top triggered by its geometry and temperature and also by battery operation (coke pushing, charging and machines traffic) significantly influence the distribution of concentrations of measured substances. However, it has been stated that in spite of divergences, over 


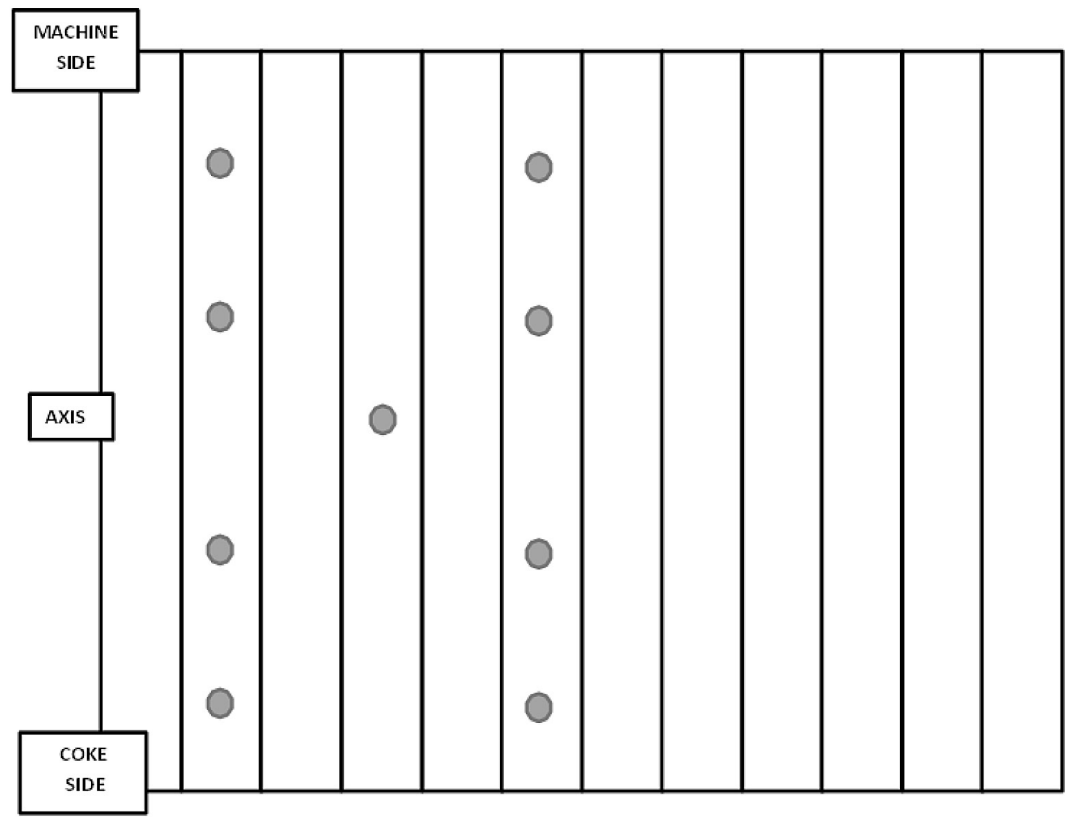

Figure 1. Location of sampling points on the battery top during emission measurements.

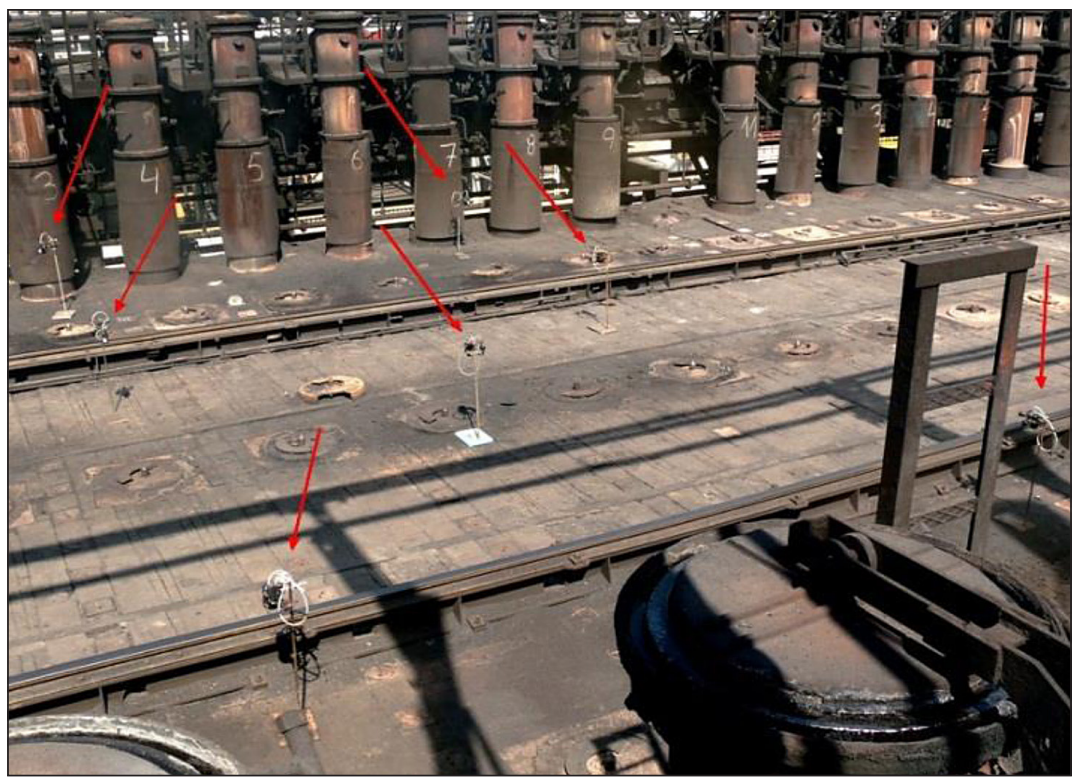

Figure 2. View of sampling points located on the battery top during emission measurements.

half of the obtained values do not differ from the average by more than $30 \%$.

Similar conclusions have been drawn from measurements carried out on the battery operating in stamping system. In this case samplers have been located on the battery service platform, in the top centre and on each of the battery sides.

Figures 4 and 5 present the levels of fugitive emission of anthracene, naphthalene and 4 PAHs (in accordance with E-RPTR requirements) and of TSP determined for individual measurement points on the battery top.
The results presented in Fig. 4 and 5 indicate a large spread of measured concentrations between individual points on the battery top. The lowest values have been measured on the battery service platform and in the battery top geometric centre, where the influence of emission from doors and coke pushing/charging operations are small and where values of the convection velocity is lower. Simultaneously, a lack of essential emission differences between the coke and machine side is observed, while difference between the service platform and measurement point on one 


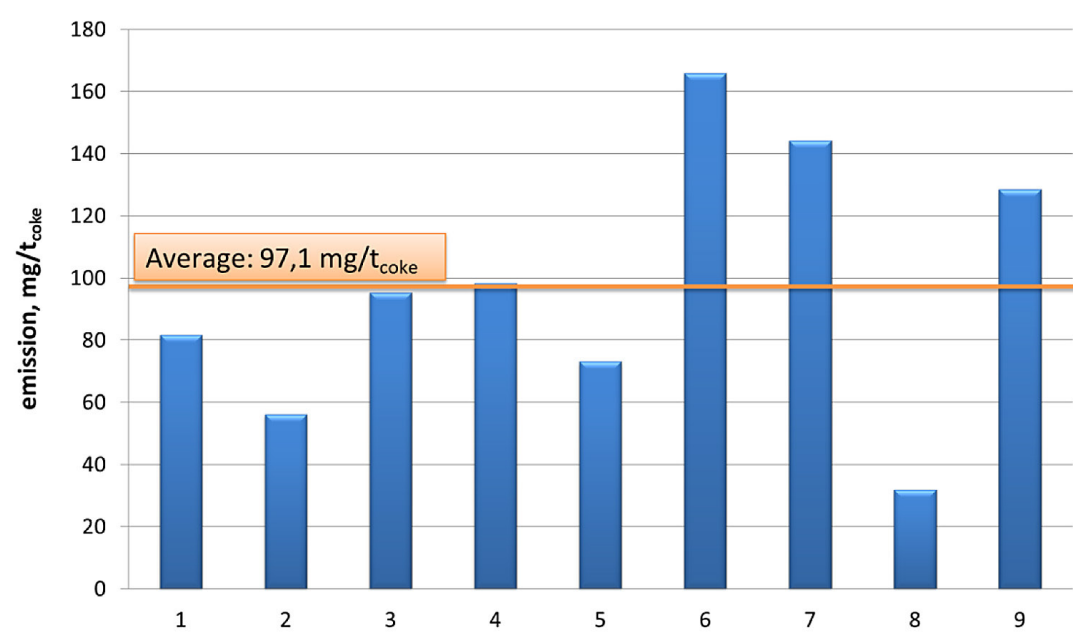

Figure 3. Fugitive 16 PAHs emission (including naphthalene, anthracene and 4 PAHs according to E-PRTR) obtained during fugitive emission measurements in 9 points over coke oven battery top.

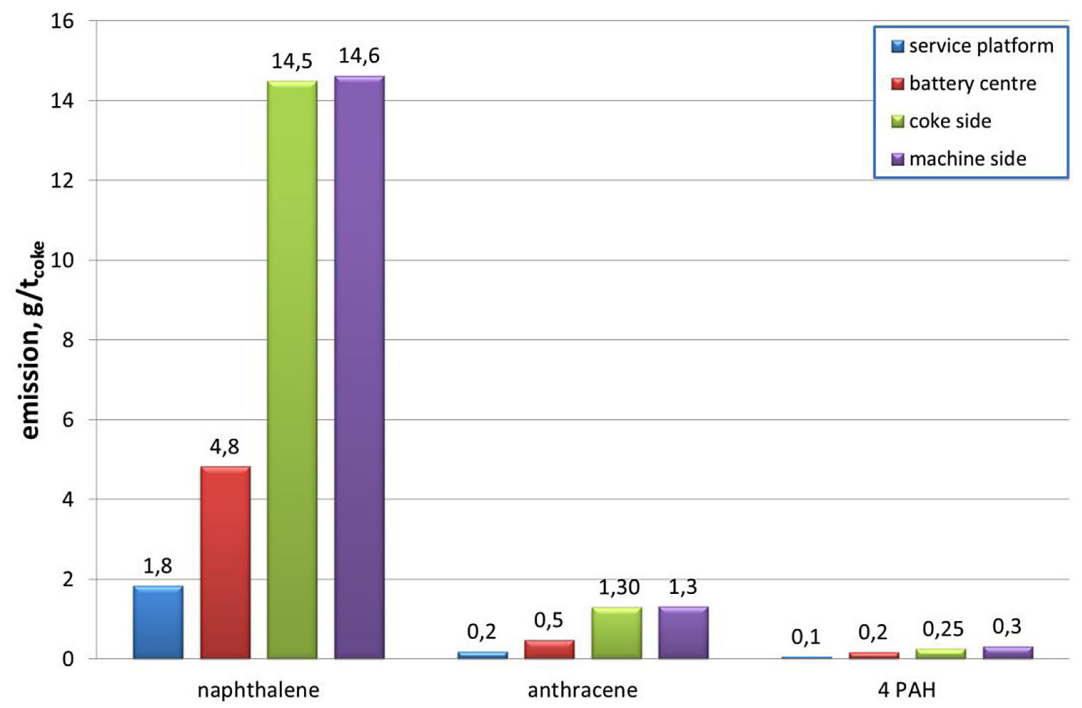

Figure 4. Fugitive emission of naphthalene, anthracene and 4 PAHs (according to E-PRTR) from coke oven battery.

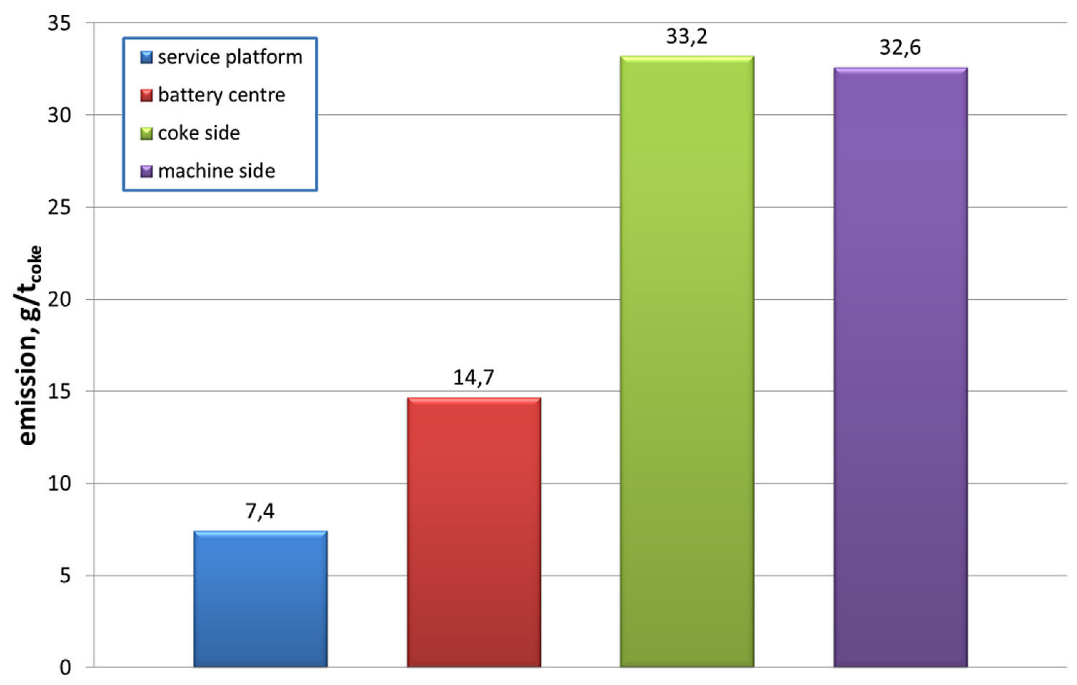

Figure 5. Fugitive emission of TSP from coke oven battery. 
of the battery sides amounts to 5 times for particulates and 8 times for naphthalene and anthracene.

Interesting conclusions, as far as the repeatability of results is concerned, have been drawn in the case of point emission from the battery lids. For this purpose, PAHs emission measurements have been carried out from closed and sealed lids. The measurements have been carried out with the use of a specially constructed sampler (Fig. 6). Samplers have been located on the lids on the machine side. The lids have been closed and sealed with the use of a traditional ceramic mortar used usually for that purpose. Four measurements have been taken in total, two on each chamber. To gather the most representative emission samples, each measurement lasted 5 hours and was carried out in the middle time of the 15 -hour coal coking cycle. The measurement has been started 5 hours after chamber charging.

The obtained results of PAHs emission indicate relative stability $\left(0.15-0.21 \mathrm{mg} / \mathrm{t}_{\text {coke }}\right)$ during individual measurements (Fig. 7). This is the effect of the minimization of the impact of atmospheric conditions on the measurement itself (measurement in a channel of the sampler).

The obtained results reveal that even closed and sealed lids are a source of fugitive PAHs emission. However, emission from closed lids

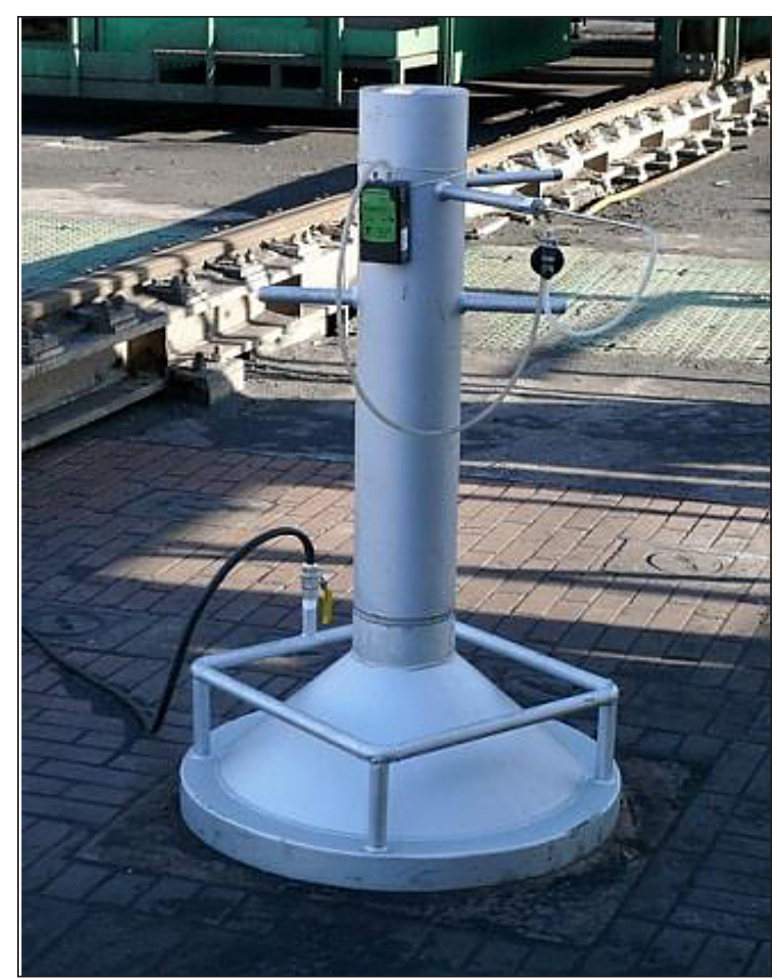

Figure 6. Funnel-shaped sampling device for emission measurements from coke oven battery lids. makes up a small part of fugitive PAHs emission (about $0.2 . \mathrm{mg} / \mathrm{t}_{\text {coke }}$ calculated on all battery lids, assuming that they have been thoroughly sealed). An outright majority of emission comes out from operations of coke production, such as coal charging and coke pushing and from unsealed point sources (smoky doors or not fully sealed lids).

\section{SAMPLING}

The issue of a proper (qualified) PAHs sampling for laboratory analyses is complicated and when it is carried out in an incompetent manner, it leads to critical errors in determining emission values. In addition is complex because of the breakdown of PAHs between the gas and particulates phase. It leads to the so called sampling artefacts [Kavouras et al. 1999, McMurry 2000], i.e. when overestimation or underestimation of the particle phase concentrations occur, mainly due to sorption or volatilization of PAH compounds on/from the filter, respectively.

Therefore, to minimize the artefacts in our investigations, special sampling systems have been used, consisting on glass container with filter head at the inlet and three layer of PUF/XAD2/ PUF (Fig. 8A) that were put into samplers, developed on the basis of EPA TO-13A method [EPA 1999], that have been located in 4 points on the battery top.

The aim of these investigations was determination of the influence of the applied sampling system on the obtained concentrations of individual pollutants.

For this purpose a series of five 6-hour measurements on the top of coke oven battery operating in stamping system have been carried out. During each measurement, four samplers were located in the above mentioned points on the top. In each of the sampler two sampling systems were placed. One consisted in a glass fibre filter and the other one - in PUF (poliurethane foam) and XAD2 sorbent system. Moreover, the experiments have been carried out to show what part of PAHs emission is present in a gas phase and what part is absorbed on particulates [Łusiak 2010].

The conducted experiments revealed that depending on the choice of sampling system, different concentration levels of the measured substances are obtained. Naphthalene and anthracene are present mainly in gas phase, whereas benzo(b) 


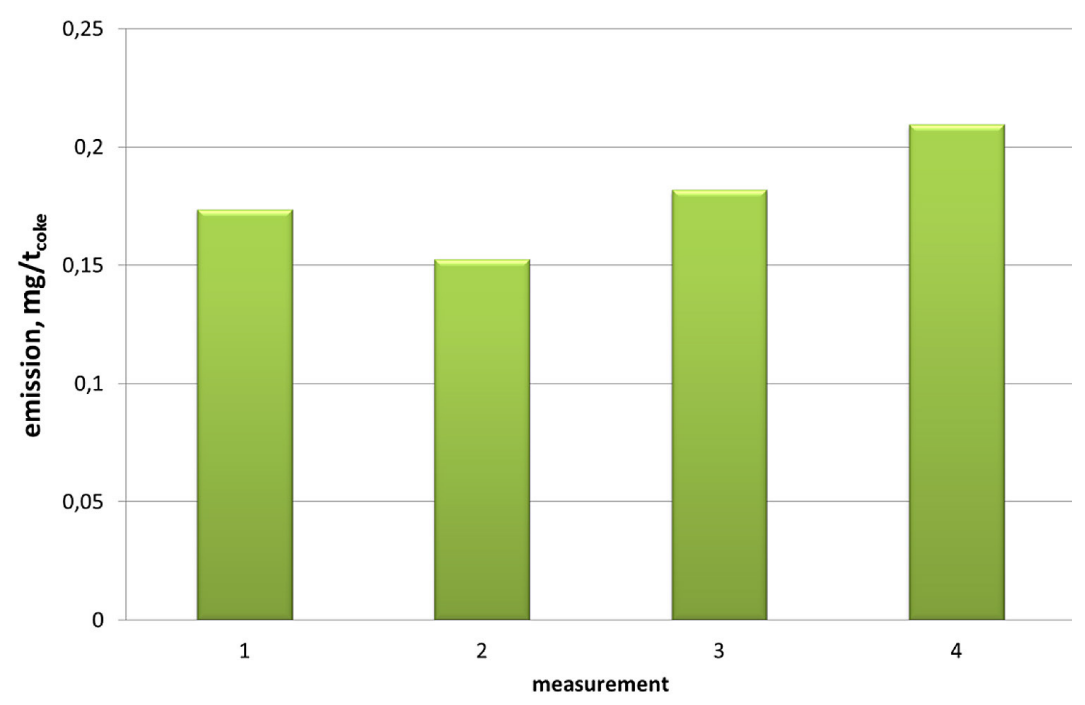

Figure 7. Fugitive 16 PAHs emission (including naphthalene, anthracene and 4 PAHs according to E-PRTR) from closed and sealed lids on coke oven battery.

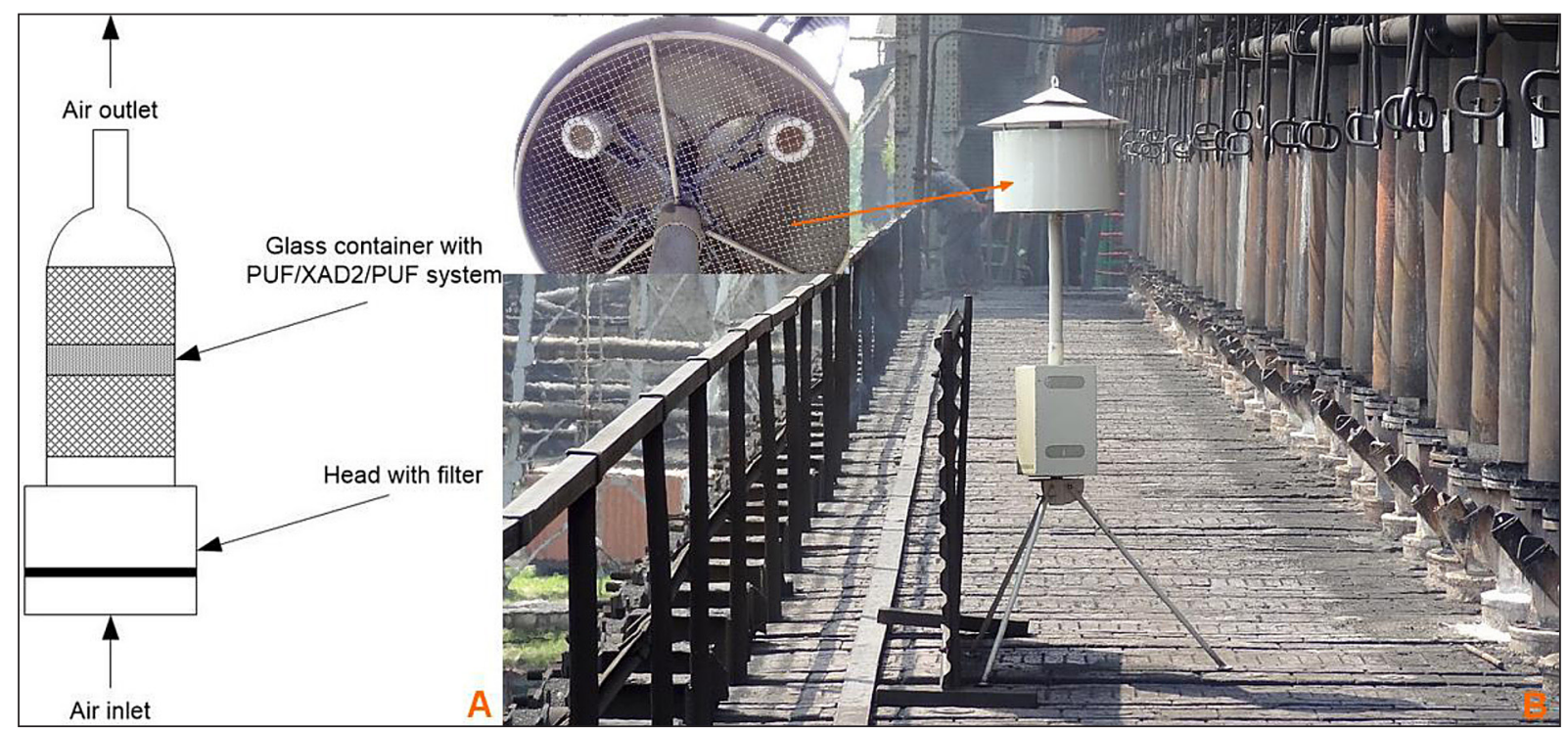

Figure 8. Sampler located on coke oven battery top during measurement.

fluoranthene, benzo(k)fluoranthene, benzo(a)pyrene and indeno $(123 \mathrm{~cd})$ pyrene condense on particulates. The results presented in Fig. 9 unambiguously show that sampling on only one carrier (filter or sorbent) causes incorrect evaluation of concentration and, in effect, improper emission value. Therefore, it is recommended to use sampling system consisting as well in filter, as a sorbent.

\section{LABORATORY ANALYSES}

The problem of determining real fugitive emission factors is linked not only with measurement, but also with the methodology of determi- nation of substances concentration in collected samples during instrumental laboratory analyses.

Samples collected during the above described measurements on the battery operating in charging system have been subjected to extraction using the Avanti Tecator extractor with the use of methylene chloride and toluene. The obtained extracts have been evaporated by Buchi vacuum evaporator. In the next step, the contents of PAHs were determined quantitatively using a gas chromatograph Fisons GC 8600 with flame-ionization detector (FID). Quantitative calculations have been carried out with the use of the internal standard method. 


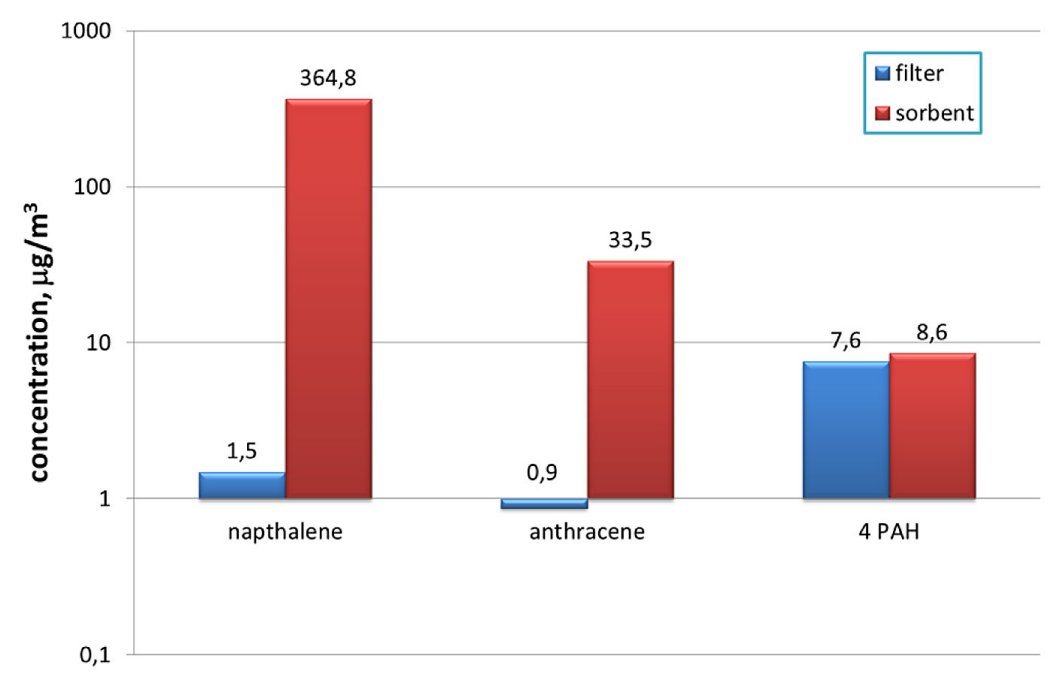

Figure 9. Differences between concentrations of naphthalene, anthracene and 4 PAHs sampled on glass fiber filters and sorbents.

In case of measurements on the battery operating in the stamping system, collected samples have been extracted according to the Soxhlet method with the use of n-hexane/diethyl ether mixture $(9 / 1, v / v)$ and the obtained fraction has been evaporated with the use of Kundern-Danish densification. Next, the contents of PAHs were quantitively determined with the use of Bischoff high efficient liquid chromatograph with fluorescence detector.

The example already shows, how different approach is possible at the laboratory stage. In spite of the fact that the analyses have been carried out in accordance with the state of the art of PAHs concentration determination, the use of different analytic equipment or another way of sample preparation might still generate differences in obtained concentrations.

The above thesis was confirmed by the experiment carried out in 2008 between four different laboratories in order to compare concentrations of 16 PAHs in one prepared sample. In this experiment, carried out within REDPAH project [REDPAH report 2009], the following laboratories, except IChPW, have taken part: Centre de Pyrolyse de Marienau (CPM), France, University of Nottingham (UNott), Great Britain and Consejo Superior de Investigaciones Científicas (CSIC), Spain. Samples were collected and prepared by CPM. Each laboratory obtained sample of identical composition (one sample was divided into 4 parts). The results of analyses revealed vast dispersion of results, as well for individual compound, as for the sum of PAHs (Fig. 10).
The divergences resulted from differences in determination methods applied in each laboratory, differences in the used analytical equipment and the purity of standards. In spite of those differences the analytical procedure concerning a sample having the same composition should lead to convergent results, what has not been obtained.

The conducted comparative experiment demonstrate how divergent results might be obtained in the case of an identical sample, because of the application of different determination procedure.

\section{DETERMINATION OF CONVECTION VELOCITY}

In order to determine emission, it is necessary to obtain information on flow rate of gases, of which concentration is measured. Therefore, in the case of measurements of fugitive emission from a coke oven battery, there is a necessity to measure convection velocity over the battery top.

Therefore, detailed measurement of air convection velocity over the battery top has been carried out according to a fixed grid (Fig. 11). Measurements have been carried out in 3 series in a few-day intervals. Measurement points were located at the battery axis and on the coke and machine sides, between the battery edge and ascension pipes. Measurement were carried out every second chamber in the axis and every forth on the battery sides.

A vertical portable channel of $200 \mathrm{~cm}$ high and $30 \mathrm{~cm}$ in diameter has been used for the convection velocity measurement, which measured 


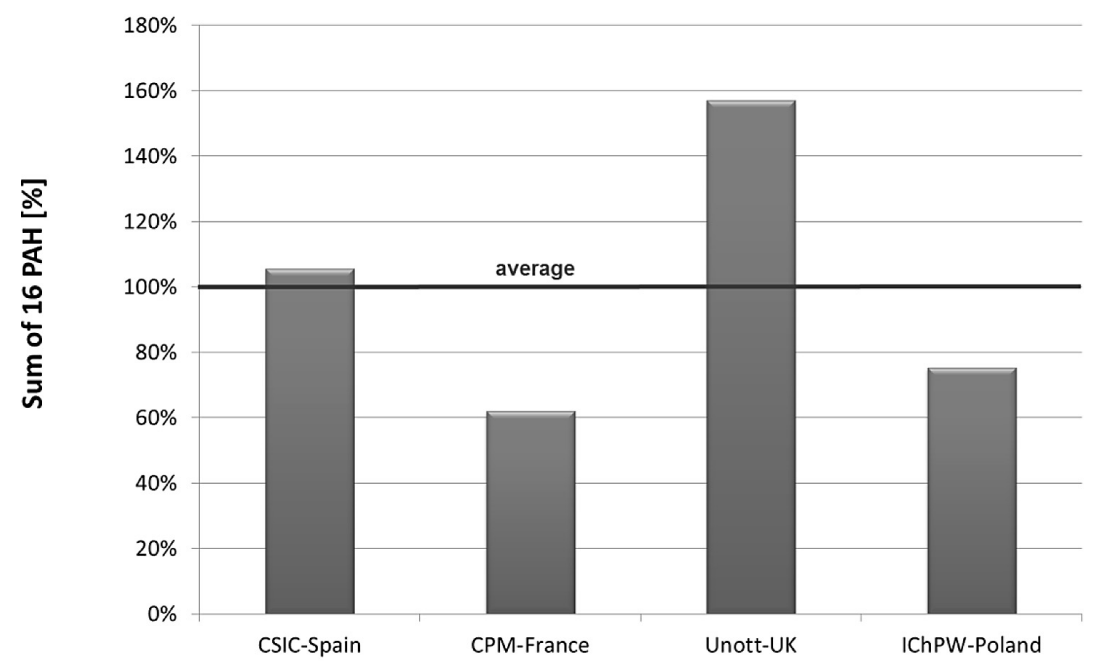

Figure 10. Results of comparative analyses of PAHs (16 PAHs) concentrations between 4 different laboratories.

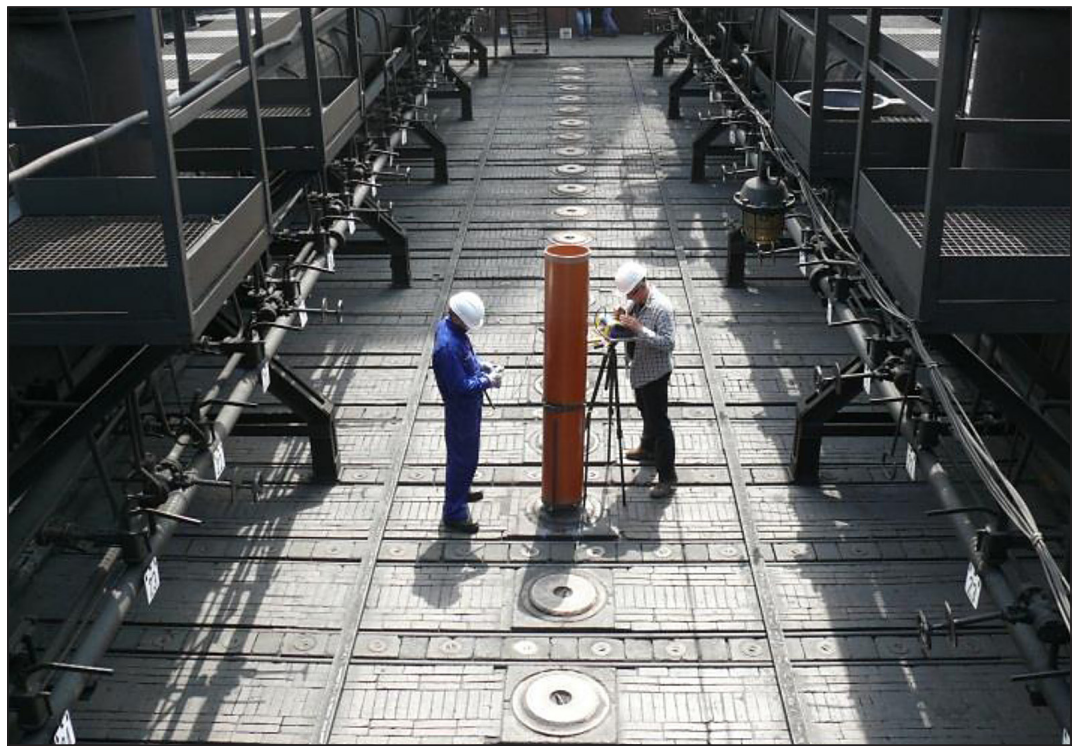

Figure 11. Convection velocity measurement on coke oven battery top

convection velocity of air from the battery top by thermoanemometer Measurement at every point lasted $1 \mathrm{~min}$. In reference to the above measurements numerical modelling of convection velocity over the battery top has also been carried out (Fig. 12). The modelling has been carried out under windless conditions.

Analysis of the obtained results indicates higher velocities on battery sides, especially at machine side. This is mainly an effect of greater disturbances in air movement on this side, caused by two phenomena: longer smoking time on the machine side (72 $\mathrm{s}$ in average in comparison to $34 \mathrm{~s}$ on the coke side) and probably by the fact that the machine side is downwind as far as the dominating wind direction is concerned.
Numerical calculations have been carried out with the use of Fluent v.12.1. - Ansys Academic CFD Research environment. A three-dimensional non-structural mesh designed from scratch in the Design Modeller program has been applied for the calculations. The number of calculation cells amounted to about 1.6 million. In the conducted simulations, the temperature of the battery top surface has been assumed based on previous thermovision surveillance of the battery top with the use of FLIR B620 infrared camera (Fig. 13).

Figure 14 presents exemplary results of carried out measurements in a form of a map of velocity distribution over 6 chambers in comparison to the distribution of convection velocity at the measurement height $(1.5 \mathrm{~m})$ obtained during the modelling in the Fluent software [Bigda 2010]. 


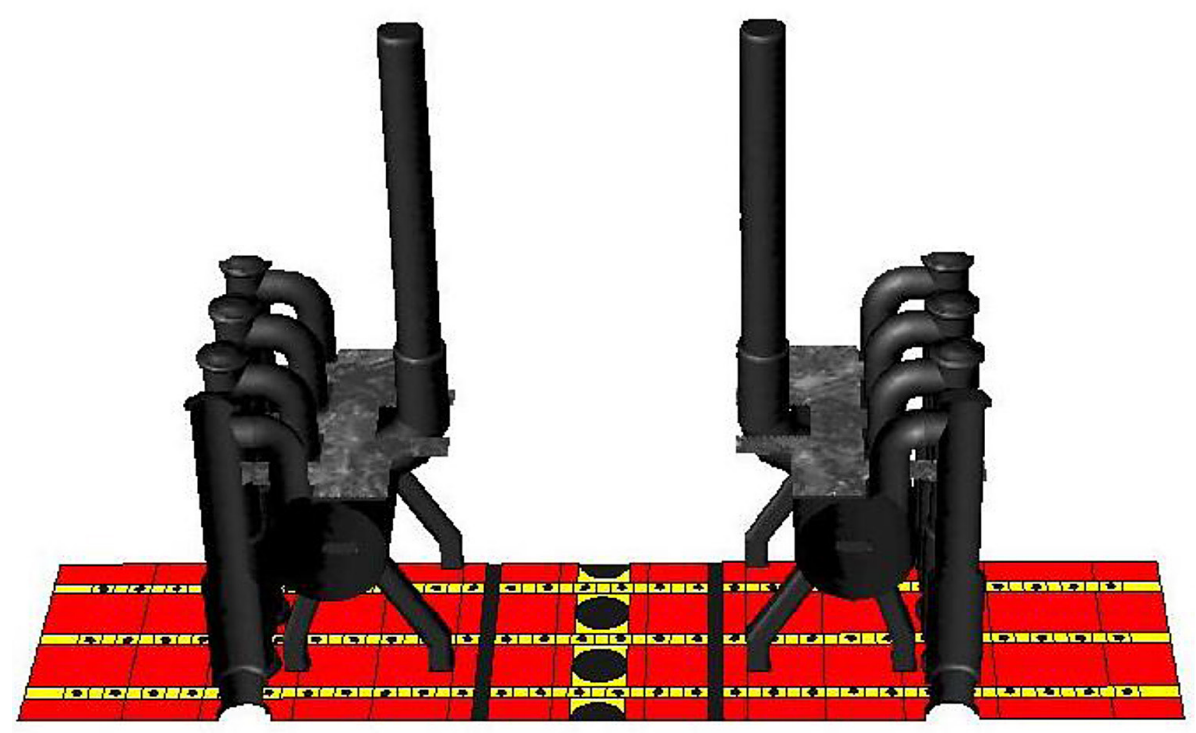

Figure 12. Geometry of top of stamping system coke oven battery used for numerical modelling in Fluent software.

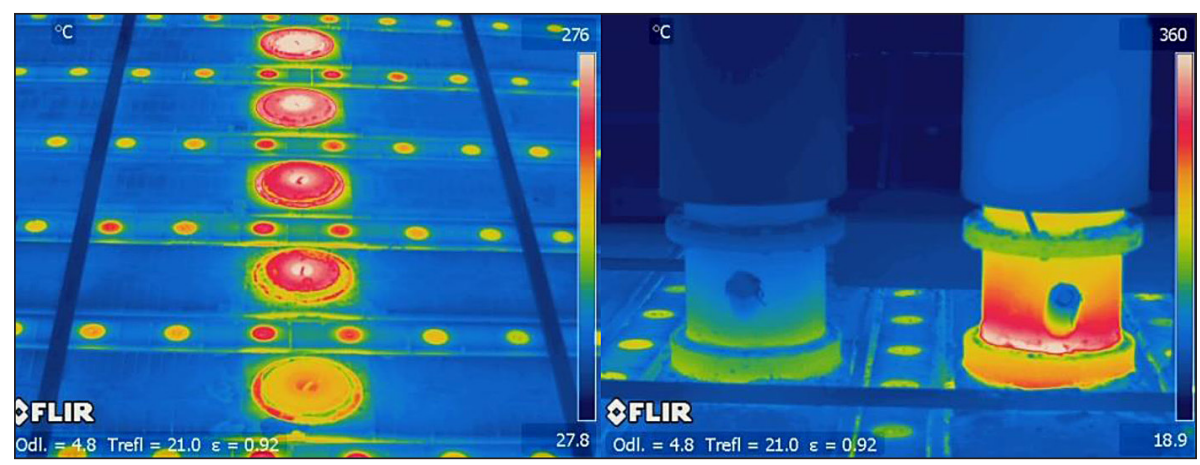

Figure 13. Thermovision data (FLIR B620) used in numerical modelling in Fluent software.

The results reveal similar profiles of the convection velocity distribution - lower velocity close to the battery axis, higher at the battery sides. Velocity values are also similar. The advantage of the model is continuity of velocity profile and including disturbances caused by the battery top geometry (proximity of ascension pipes, where velocity increase is observed), what is hard to be registered by measurements (measurement mesh should be then very fine).

The similarity of the results from the model and those obtained with the use of measurements suggest that the advantage is on the side of mathematic modeling, because there are no discontinuity elements appearing in the case of measurements. In addition, after preparation and verification of the used model the modelling proves to be easier to execute and moreover allows modifying conditions influencing convection velocity (modification of the battery top geometry and its temperature, ambient temperature as well as wind speed and direction).

\section{DISCUSSION}

All four above discussed groups of factors have an influence on the final value of determined emission. Analysis of the results and the authors' long experience indicate that relatively the smallest error is made at the stage of instrumental analyses in laboratory. In turn, this area is most often discussed in scientific circles.

On the other hand, in coke-makers circles prevail the conviction on the lack of possibilities to carry out repeatable measurements of fugitive emission of trace pollutants from a coke oven battery.

Carried out studies explicitly revealed a direct quantitative relationship between technical plant 


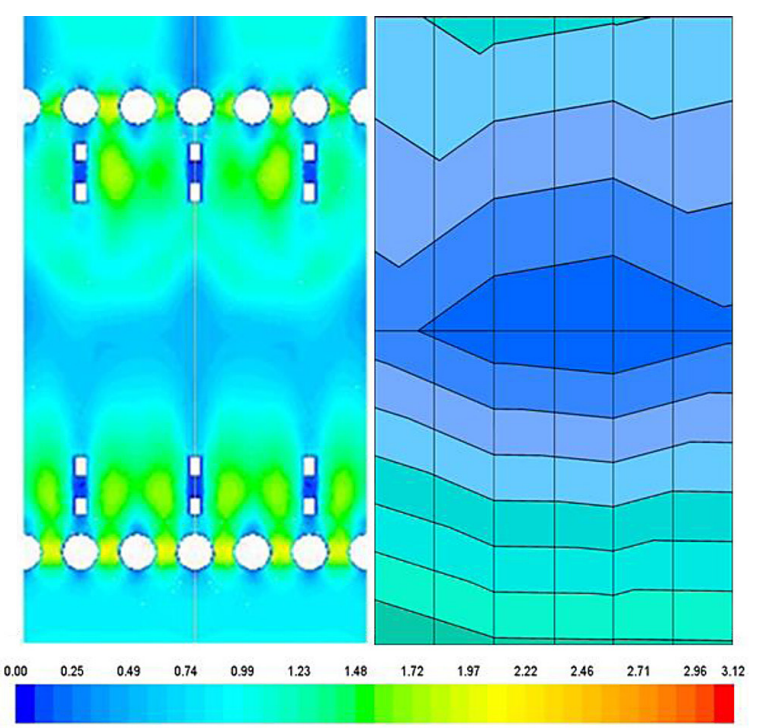

Figure 14. Determination of convection velocity over coke oven battery top: left - from Fluent modelling, right - from measurements (scale in $\mathrm{m} / \mathrm{s}$ ). CS - coke side, MS - machine side.

condition and the level of PAHs fugitive emission [REDPAH report 2009]. Measurements have been carried out with the use of identical method for batteries of the same construction and of identical technological parameters, as well as for similar composition of coal blend (Fig. 15).

While in the case of a "new" battery emission amounts to ca. $100 \mathrm{mg} / \mathrm{t}_{\text {coke }}$, in the case of an "old" battery it oscillates around $1,400 \mathrm{mg} / \mathrm{t}_{\text {coke }}$. It should be, however, pointed out that during measurements the "old" battery was in a very bad technical condition (shortly before shut down).

The published papers of experts confirm the observed and above-presented divergences
(Fig. 16). Commonly quoted subject literature indicates differences in PAHs emission at the level of two orders of magnitude. Such big differences, on the one hand, follow from different technical condition of batteries subjected for studies, and from the second - from significant differences between methods of emission measurement.

For properly operating batteries the level of PAHs emission should be in the range of $100-1,000 \mathrm{mg} / \mathrm{t}_{\text {coke }}$. Higher values indicate operational errors or of use or inadequacy of technical battery equipment.

To obtain reliable emission factors, during measurement of fugitive emission from a coke oven battery, technological, scientific and analytical attitudes should be integrated. On the other hand, since there are no acknowledged methods of determining the level of fugitive emission from the battery, it is crucial to undertake numerous attempts for its experimental determination, even at the level of approximation.

The above discussed problems and the presented results reveal how important each element is in determining fugitive emission from a coke oven battery. Starting from the location of the measurement points on the battery top, through the application of a proper sampling system and laboratory analyses and ending with measurement of convection velocity over the top. Each element generates errors that influence the value of final emission measurement. It seems that the only option is to carry out a large number of repetitions at each stage to eliminate divergent values and obtain a value carrying the least error. However, this recommendation meets with strong resistance

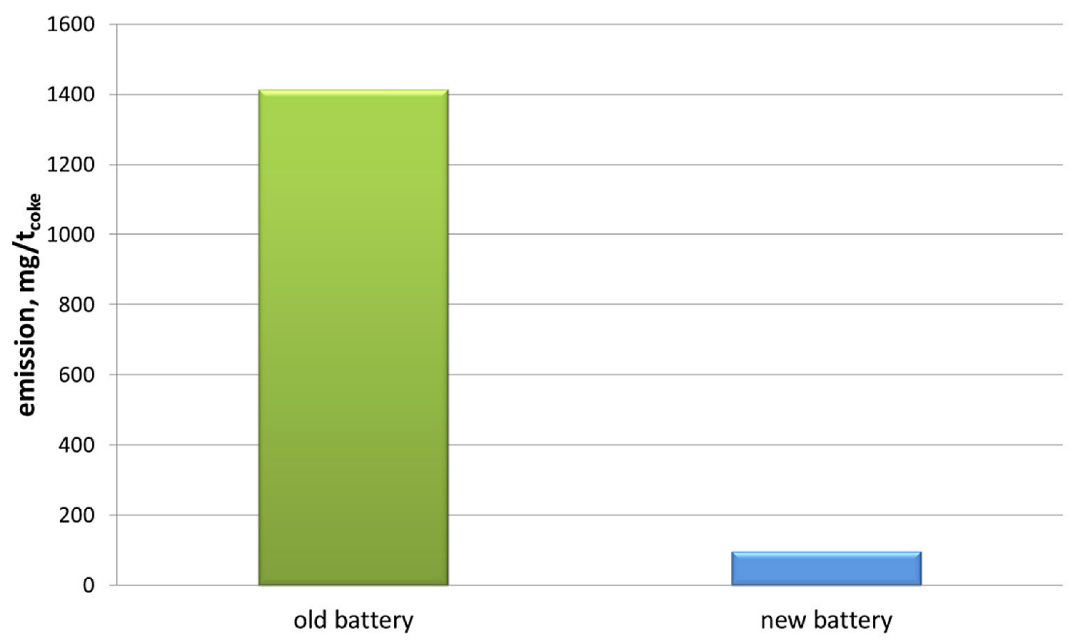

Figure 15. Comparison of obtained results of average fugitive emission measurements of PAHs (sum of 16 compounds) for old and new coke oven battery. 


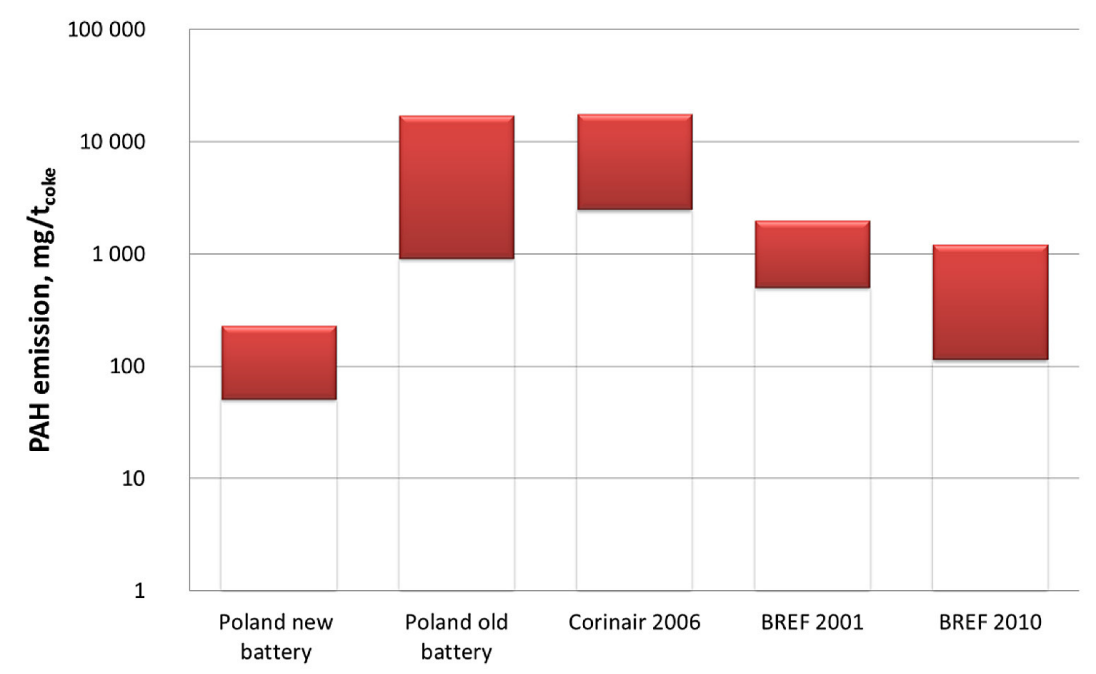

Figure 16. Comparison of obtained results of fugitive emission measurements of PAHs (sum of 16 compounds)

from the side of producers, because of the high costs of extensive measurement campaigns supported by an advanced instrumental analysis.

\section{CONCLUSIONS}

The facts presented the above substantiate large divergences in the results obtained during measurement of fugitive emission from coke oven batteries. Due to the large relationship on atmospheric conditions, battery operations and battery technical condition this form of emission continues to be a challenge for measurement staff.

The presented material is an attempt at a crosssectional presentation of issues linked with the quantitative determination of fugitive emission from coke oven batteries, discussed here in the example of PAHs emission considered as characteristic group of substances for coal coking process. The issue is both crucial and complex. Operators of coke plant installations will be increasingly subjected to social and administrative pressure due to the implementation of the E-PRTR system. Because of its open character the system forms a sort of database and a source of information for coke producers facilitating the verification of their own measurements and calculations.

The problem of emission monitoring is to a growing extent subject of exchange of information between European coking plants. It concerns both common European research projects and bilateral exchange of experience between coking plants.

One should express the conviction that a broad discussion on the issue and the unification of research methodology will lead to the limitation of pollutants emission from the process of coke production. This question is exceptionally crucial for improving the acceptance of our branch of industry by the society in the EU.

\section{Acknowledgements}

The paper has been made within the framework of the project No. POIG.01.01.02-24-017/08 "Smart Coke Plant Meeting the Requirements of Best Available Techniques" co-financed by the European Regional Development Fund (ERDF).

INNOWACYJNA GASOPODARARKAEGA SPOINOSG
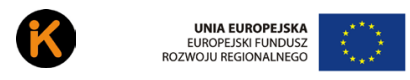

\section{REFERENCES}

1. Antill, J.F. 1991. Environmental Improvements Realised at United Kingdom Coking Plants Measured by BCRA under the Aegis of ECSC Supported Research Study. The Year-Book of the Coke Oven Managers' Association, 148-172.

2. Bigda, R. 2010. Model of environmental monitoring of a coke oven battery, operating "online", which includes monitoring of fugitive emission. Quarterly Report of Project "Smart Coke Plant Satisfying the Requirements of Best Available Techniques" (No. POIG.01.01.02-24-017/08), (not published, in Polish).

3. Chitsan, L., Naiwei, L., Pao-Erh, C., Jen-Chin, Y., Sun, E. 2007. Fugitive Coke Oven Gas Emission Profile by Continuous Line Averaged Open-Path Fourier Transform Infrared Monitoring. Journal of the Air \& Waste Management Association, 57 (4), 472-479.

4. Eisenhut, W. 1990. Trace Element Mass Balance in the Materials Flow in Coke Oven Plant. Proceed- 
ings of EEC Information Days Meeting, 244-250.

5. EPA Method TO-13A 1999. Determination of Polycyclic Aromatic Hydrocarbons (PAHs) In Ambient Air Using Gas Chromatography/Mass Spectrometry (GC/MS).

6. Fischer, R. (2001). Sources, measurement and control of fugitive emissions in the cokemaking process, The Coke Oven Managers' Year-Book, 87-105.

7. Guidance Document for the implementation of the European PRTR (2006). European Commission, Environment DG.

8. Hereźniak, W., Jarno, M., Sobolewski, A., Ściążko, M. and Warzecha, A. 2008. Strategic issues of Polish and world coke making, Karbo, Special Issue (in Polish).

9. Hermia, J., Vigneron, S. and Slingeneijer, C. 1992. Odour Characterisation and Control of Volatile Odoriferous Compounds in Coke and Steel Industries. Studies in Environmental Science 51, 225-230

10. Kavouras, I..G., Lawrence, J., Koutrakis, P., Stephanou, E.G., Oyola, P. 1999. Measurement of particulate aliphatic and polynuclear aromatic hydrocarbons in Santiago de Chile: source reconciliation and evaluation of sampling artifacts, Atmospheric Environment, 33, 4977-4986

11. Klein, F. 1990. Community Research on Pollution by Polycyclic Aromatic Hydrocarbons in Coke Plants. Proceedings EEC Information Days Meeting, 235-240.

12. Łusiak, T. 2010. Particulates sampling and determination of PAHs content in TSP emitted on coke oven battery top, Report 53/IChPW/10 (not published, in Polish).

13. McMurry, P.H. 2000. A review of atmospheric aerosol measurements, Atmospheric Environment, 34, 1959-1999.

14. Okuda, K., Yamasaki, K. and Watanabe, H. 2006.
A Solution to Prevent Gas Emission from the Coke Oven Door. Aistech-Conference Proceedings, 1, 563-569.

15. Optical Remote Sensing for emission characterization from non-point sources (2006). Final ORS Protocol, EPA.

16. Reduction of Polycyclic Aromatic Hydrocarbon (PAHs) Emission from Coke Oven Battery (REDPAH) 2009. Final Report, Contract No. RFCRCT-2005-00005, European Comission.

17. Regulation (EC) No 166/2006 of the European Parliament and of the Council of 18 January 2006 concerning the establishment of a European Pollutant Release and Transfer Register and amending Council Directives 91/689/EEC and 96/61/EC

18. Sobolewski, A. and Ściążko, M. 2006. Best Available Techniques (BAT) - Guidelines for the coke industry, Institute for Chemical Processing of Coal, Zabrze (in Polish).

19. Telenga-Kopyczyńska, J.; Lajnert, R. and Sobolewski, A. 2009. Co-operation of coke plant within determination of emission of air pollutants within the frame of the PRTR reporting, Chemik NaukaTechnika-Rynek, 62 (10), 368-373 (in Polish).

20. Telenga-Kopyczyńska, J, Lajnert, R, Robak, J. and Sobolewski, A 2010. Environmental assessment of coke plant in the light of the new regulations, Contemporary achievements in the protection of atmospheric air, red. Musialik-Piotrowska, A. and Rutkowski, J.D. Proceedings of „POL-EMIS 2010” Environmental Conference in Polanica-Zdrój, Poland (in Polish).

21. Thomas, B.S. 1990. Joint Investigations into the Measurement of Benzene, Toluene and Xylene in and Around Coke Works. Proceedings EEC Information Days Meeting.

22. Thorneloe, S. 2007. Evaluation of Fugitive Emissions Using Ground-Based Optical Remote Sensing Technology, Report EPA/600/R-07/032. 